\title{
Control of the Density of Polymer Brushes Prepared by Surface-Initiated Atom Transfer Radical Polymerization
}

\author{
Zhiyi Bao, Merlin L. Bruening, Gregory L. Baker* \\ Department of Chemistry, Michigan State University, East Lansing, MI 48824, USA
}

bruening@msu.edu, bakerg@msu.edu

\section{Supporting Information}

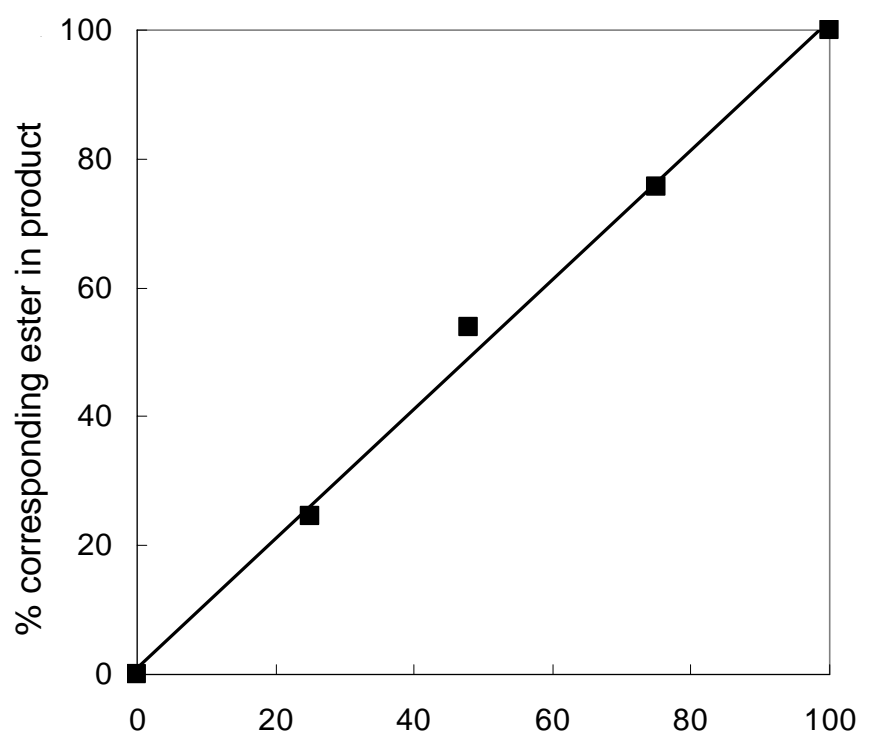

$\% 1$ (2-BPB) in starting mixture

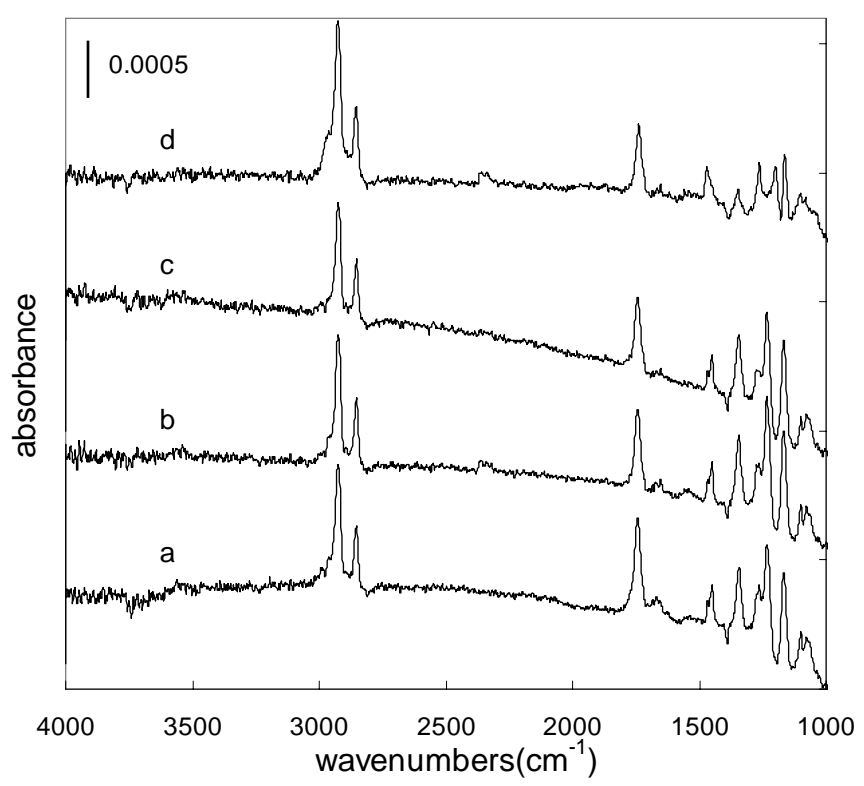

Figure S1. Results from ${ }^{1} \mathrm{H}$ NMR analysis of the reaction of 2-bromopropionyl bromide (2$\mathrm{BPB})$ and 2-methylpropionyl bromide (2-MPB) with hexadecanol. The ratio of the two esters in the product was determined by integration of the $\alpha$-methyl peaks in the ${ }^{1} \mathrm{H}$ NMR spectrum.
Figure S2. Reflectance FTIR spectra of diluted-initiator monolayers on gold substrates prepared from mixtures of 2bromopropionyl bromide (2-BPB) and 2methylpropionyl bromide (2-MPB). (a) $100 \%$ 2-BPB, (b) 50\% 2-BPB, (c) 25\% 2$\mathrm{BPB}$, (d) 1\% 2-BPB. 
Table S1. HEMA polymerization rates from silicon substrates at various initiator densities ${ }^{a}$

\begin{tabular}{ccccc}
\hline $\begin{array}{c}\text { initiator composition } \\
(\% \text { 3) }\end{array}$ & $\begin{array}{c}\text { initiator density }^{c} \\
\left(\text { sites/nm }{ }^{2}\right)\end{array}$ & $\begin{array}{c}\text { PHEMA thickness } \\
\text { at } 8 \mathrm{~h}(\mathrm{~nm})\end{array}$ & $\begin{array}{c}\text { polymerization } \\
\text { rate }(\mathrm{nm} / \mathrm{hr})^{d}\end{array}$ & $\begin{array}{c}\text { normalized } \\
\text { rate }^{e}(\mathrm{~nm} / \mathrm{hr})\end{array}$ \\
\hline 100 & 1.5 & 213 & 36 & 36 \\
50 & 0.77 & 150 & 28 & 55 \\
10 & 0.15 & 23 & 4.9 & 49 \\
5 & 0.077 & 16 & 3.7 & 74 \\
1 & 0.015 & 5.7 & 1.3 & 130
\end{tabular}

a. polymerization conditions: $[\mathrm{CuCl}]=27.5 \mathrm{mM},\left[\mathrm{CuBr}_{2}\right]=8.0 \mathrm{mM},\left[2,2^{\prime}\right.$-bipyridine $]=78 \mathrm{mM}$, in $20 \mathrm{~mL}$ of a $1: 1(\mathrm{v}: \mathrm{v})$ mixture of HEMA and $\mathrm{H}_{2} \mathrm{O}([\mathrm{HEMA}]=4 \mathrm{M})$ at $28^{\circ} \mathrm{C}$. $b$. based on the ratio of 11-(2-bromo-2-methyl)propionyloxy)undecyldimethylchlorosilane (initiator 3) and (11-(2,2-

dimethyl)propionyloxy)undecyldimethylchlorosilane (diluent 4) $c$. assuming full coverage $=1.54$ sites $/ \mathrm{nm}^{2}{ }^{1}$ c. defined as the slope of the line defined by least square fits to the data in Figure 5. $e$. defined as the film growth rate divided by fractional coverage of the surface by initiator.

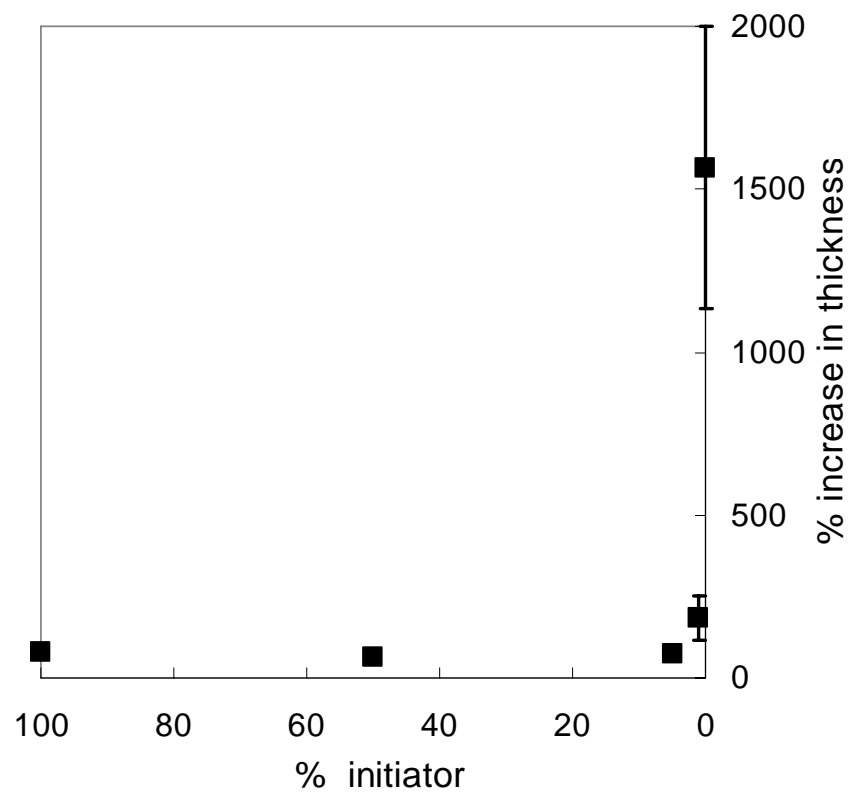

Figure S3. Aqueous swelling of brushes prepared by polymerization of HEMA from diluted-initiator monolayers on gold substrates. The points are the average of measurements from two data sets, and the limits of the error bars are the \% increase in thickness measured from the two runs. 
Table S2. HEMA polymerization rates from silicon substrates using trimethylsilyl chloride and (11-(2,2-dimethyl)propionyloxy)undecyldimethylchlorosilane as diluents. ${ }^{a}$

\begin{tabular}{|c|c|c|c|c|}
\hline initiator composition $^{b}$ & $\begin{array}{l}\text { initiator layer } \\
\text { thickness (nm) }\end{array}$ & $\begin{array}{l}\text { PHEMA thickness } \\
\text { at } 8 \mathrm{~h}(\mathrm{~nm})\end{array}$ & $\begin{array}{l}\text { polymerization } \\
\text { rate }(\mathrm{nm} / \mathrm{hr})^{c}\end{array}$ & $\begin{array}{l}\text { normalized } \\
\text { rate }^{\mathrm{d}}(\mathrm{nm} / \mathrm{hr})\end{array}$ \\
\hline $100 \% 3^{e}$ & 1.4 & 212 & 32 & 32 \\
\hline $50 \% 3,50 \% 4^{e}$ & 1.4 & 151 & 24 & 48 \\
\hline $100 \% 3^{f}$ & 1.4 & 220 & 36 & 36 \\
\hline 50\% 3, 50\% $\mathbf{T M S C l}^{f}$ & 0.4 & 23 & 4 & 8 \\
\hline \multicolumn{5}{|c|}{$\begin{array}{l}\text { a. polymerization conditions: }[\mathrm{CuCl}]=27.5 \mathrm{mM},\left[\mathrm{CuBr}_{2}\right]=8.0 \mathrm{mM},[2,2 \text { '-bipyridine }]=78 \mathrm{mM} \text {, in } \\
20 \mathrm{~mL} \text { of a } 1: 1(\mathrm{v}: \mathrm{v}) \text { mixture of } \mathrm{HEMA} \text { and } \mathrm{H}_{2} \mathrm{O}([\mathrm{HEMA}]=4 \mathrm{M} \text { b. based on the ratio of } 11-(2- \\
\text { bromo-2-methyl)propionyloxy)undecyldimethylchlorosilane (initiator } 3) \text { and }(11-(2,2- \\
\text { dimethyl)propionyloxy)undecyldimethylchlorosilane (diluent } 4) \text { or TMSCl used in the anchoring } \\
\text { step. } c \text {. defined as the slope of the line defined by least square fits to the } 0-2 \mathrm{hr} \text { data in Figure } 8 . d \text {. } \\
\text { defined as the polymerization rate divided by fractional coverage of the surface by initiator. } e \\
\text { samples and } f \text { samples were run concurrently. }\end{array}$} \\
\hline
\end{tabular}

\section{Reference}

1. $\quad$ Sander, L. C.; Wise, S. A., J. Chromatog. 1984, 163-181, 163. 